Old Dominion University ODU Digital Commons

2012

\title{
Consuming Direct-to-Consumer Genetic Tests: The Role of Genetic Literacy and Knowledge Calibration
}

Yvette E. Pearson

Old Dominion University, ypearson@odu.edu

Yuping Liu-Thompkins

Old Dominion University, YXXLiu@odu.edu

Follow this and additional works at: https://digitalcommons.odu.edu/philosophy_fac_pubs

Part of the Business Law, Public Responsibility, and Ethics Commons, Ethics and Political Philosophy Commons, and the Genetics Commons

\section{Repository Citation}

Pearson, Yvette E. and Liu-Thompkins, Yuping, "Consuming Direct-to-Consumer Genetic Tests: The Role of Genetic Literacy and Knowledge Calibration" (2012). Philosophy Faculty Publications. 45.

https://digitalcommons.odu.edu/philosophy_fac_pubs/45

\section{Original Publication Citation}

Pearson, Y., \& Liu-Thompkins, Y. (2012). Consuming direct-to-consumer genetic tests: The role of genetic literacy and knowledge calibration. Journal of Public Policy \& Marketing, 31(1), 42. doi:10.1509/jppm.10.066

This Article is brought to you for free and open access by the Philosophy \& Religious Studies at ODU Digital Commons. It has been accepted for inclusion in Philosophy Faculty Publications by an authorized administrator of ODU Digital Commons. For more information, please contact digitalcommons@odu.edu. 


\title{
Consuming Direct-to-Consumer Genetic Tests: The Role of Genetic Literacy and Knowledge Calibration
}

\author{
Yvette E. Pearson and Yuping Liu-Thompkins
}

\begin{abstract}
As direct-to-consumer marketing of medical genetic tests grows in popularity, there is an increasing need to better understand the ethical and public policy implications of such products. The complexity of genetic tests raises serious concerns about whether consumers possess the knowledge to make sound decisions about their use. This research examines the effects of educational intervention and feedback on consumers' genetic literacy and calibration-the gap between consumers' actual knowledge and how much they think they know. The authors find that consumers' genetic knowledge was generally low and that people tended to underestimate their knowledge level. Furthermore, consumers' perceived rather than actual knowledge levels drove attitude and purchase intention. Regarding the effect of educational intervention, exposure to an online educational module improved both genetic knowledge and calibration. Offering instant feedback resulted in greater knowledge gain than delayed feedback. The worst learning outcome occurred when feedback was both delayed and brief. On the basis of these findings, the authors offer recommendations for formulating ethically sound public policies in this area.
\end{abstract}

Keywords: genetic literacy, knowledge calibration, genetics education, direct-to-consumer marketing, marketing ethics

D irect-to-consumer (DTC) marketing of genetic tests continues to expand, as an increasing number of companies enter the marketplace hoping to profit from the sale of genetic testing services. ${ }^{1}$ Currently, at-home genetic tests reportedly represent $\$ 80$ million in total revenue, with close to 20 companies competing in the field (Terry 2008). Two recent newsworthy events highlight the growing interest in such genetic tests. In the first case, Walgreens had planned to sell an over-the-counter genetic test for certain genetic diseases and sensitivity to some substances (e.g.,

\footnotetext{
${ }^{1}$ Although there are several uses for genetic testing (e.g., paternity, research), this article is concerned primarily with tests that directly analyze human DNA for variations associated with diseases.
}

Yvette E. Pearson is Associate Professor of Philosophy, Department of Philosophy and Religious Studies, and Co-Director of the Institute for Ethics and Public Affairs (e-mail: ypearson@odu.edu), and Yuping Liu-Thompkins is Fellow, Society for New Communications Research, and Associate Professor of Marketing, and E.V. Williams Faculty Fellow, College of Business and Public Administration (e-mail: YXXLiu@ odu.edu), Old Dominion University. The authors thank the Faculty Proposal Preparation Program at Old Dominion University, which provided partial support for this project. They also acknowledge the helpful input from participants at the 16th International Vincentian Business Ethics conference. Madhu Viswanathan served as associate editor for this article. caffeine, medications). The company decided against it for the time being only after receiving a letter from the Food and Drug Administration questioning the legality of the practice (Stein 2010). In the second case, University of California, Berkeley, announced a plan to offer genetic testing to all 5500 incoming freshmen in fall 2010 (Colliver 2010). This experiment was designed to "capture [students'] imaginations" and promote "deeper learning" (University of California, Berkley 2010). Both events point to the potential expansion of DTC genetic test use.

Awareness of the probable social and ethical implications of DTC marketing of genetic tests is imperative given the expanding prevalence of the practice. While concerns about marketing health-related products are not new, combining the complexity of medical genetics with DTC marketing raises additional concerns about people's ability to make knowledgeable decisions. Even when consumers receive tests from other sources (e.g., as a gift), concerns about their lack of knowledge remain. Although genetics, which focuses on individual genes, is in some cases relatively straightforward (e.g., single-gene traits or maladies), laypersons' understanding of genetics remains limited. Moving beyond genetics to genomics, which refers to an organism's entire set of genes and their interaction with the environment, a clear grasp of the field eludes a wider audience. As Christensen et al. (2010) explain, we are faced not only with an information deficit but pervasive, significant misconceptions about genetic science. This raises questions 
about whether informed consent requirements can be met and whether DTC marketing might encourage inappropriate use of genetic tests and promote a misuse of health care resources (McGuire et al. 2009). Furthermore, in contrast to traditional use of genetic tests for diagnostic purposes, people are now motivated by other factors to undergo genetic tests. For example, some undergo genetic tests merely out of curiosity rather than because they have a family history of a particular disease.

To date, much of the literature on genetic testing has focused on company and government practices (Berg and Fryer-Edwards 2008; Liu and Pearson 2008; WilliamsJones 2003; William-Jones and Ozdemir 2008). There are few data about how consumers actually respond to DTC marketing of genetic tests or what factors affect their purchase decisions. One exception is a recent study by McGuire et al. (2009), which examined how social networkers responded to DTC genetic tests. They found a fairly high level of interest among their respondents, with $64 \%$ reporting that they would consider using such tests and another $6 \%$ who had already used such tests. Within the context of the genetic testing experiment at the University of California, Berkeley, Gross (2010) found most students she interviewed to be enthusiastic about using DTC genetic tests. One incoming freshman expressed his preference for a "free DNA test over a book any day" because he viewed a test as being "more modern and relevant" (Gross 2010). However, reactions in the public commentary have been mixed. Some doubt the ethical soundness of such an experiment, while others commend it.

The creation of ethically sound public policy in this area requires more research to assess consumers' readiness to process information within the context of DTC marketing of genetic tests. Among other things, it is necessary to examine consumers' genetic literacy, the impact of marketing tactics on their decisions, and their ability to comprehend and use test results in making health-related decisions. One study that is currently addressing the latter is the Scripps Genomic Health Initiative, a longitudinal study of the psychological and behavioral effects of using DTC tests (Bloss, Schork, and Topol 2011). Supplementing this initiative, our research focuses on the decision making context before undergoing such tests. More specifically, we examine actual versus perceived genetic literacy of consumers likely to be exposed to DTC marketing of genetic tests. We also examine the influence of certain educational interventions on genetic literacy and the gap between objective and subjective assessments of genetic knowledge.

Our decision to focus on genetic literacy and the gap between objective and perceived knowledge stems from the complexity of genetic science and its likely impediment to informed decision making about genetic testing. Marketing information-intensive products such as genetic tests requires sensitivity to consumers' information-seeking and integration processes. Therefore, a deeper understanding of consumers' literacy and knowledge calibration will help better gauge the likely impact of DTC marketing of genetic tests and guide public policy in this area. Literature on consumer literacy deficits in other areas, such as nutrition and finance, has examined consumer knowledge and self-efficacy separately. However, it has not linked knowledge and self-efficacy to examine the gap between the two as we explore in the current research. We argue that to fully understand consumers' knowledge state, it is necessary to determine not only knowledge and self-efficacy but also the relationship between the two as captured by knowledge calibration.

\section{Genetic Literacy and Knowledge Calibration}

We now turn to an examination of genetic literacy and knowledge calibration in the context of DTC marketing of genetic tests. We first review the current state of genetic literacy as revealed by previous research. Then, drawing from the consumer psychology literature, we formally define knowledge calibration and point out the consequences of inaccurate knowledge calibration. As our discussion makes clear, a gap between people's actual and perceived knowledge can affect their decision making in various ways. Therefore, acknowledging and addressing this problem is as critical as tackling the knowledge deficits themselves.

\section{Genetic Literacy: An Uncertain Picture}

Genetic literacy refers to a person's basic knowledge about genetic science. It encompasses key genetic concepts, such as gene expression, transmission, and a basic understanding of the effect of genes on individual health. McInerny (2002) expresses concern about the public's scientific literacy and inability to distinguish science from pseudoscience, making the deficits in genetic literacy unsurprising. After all, genetics is a complex science, and the value of a gene often depends on myriad other characteristics of the organism and its environment. As Condit (2010) shows, people's understanding of heredity does not translate to an understanding of basic genetics. Knowing that genes affect health often exists alongside a complete failure to understand precisely how they do so. This is of particular concern, given Condit's observation that the failure to understand genetics is magnified within the context of genetic testing. Consequently, ethical questions should be raised about external influences on consumer decisions, such as the quality of available information and the marketing tactics used to convey it.

Empirical assessments of the public's knowledge of genetics and genetic testing are scant (Christensen et al. 2010) and somewhat mixed. A few studies find relatively high levels of genetic knowledge within their study populations (Etchegary et al. 2010; Rose et al. 2005). In contrast, an assessment of genetic knowledge by Bowling, Huether, et al. (2008) using the Genetic Literacy Assessment Instrument (GLAI) reveals a significant deficit among even undergraduate life sciences students, despite having had some college-level science education with a significant genetics component. The mean precourse GLAI score among the students in their study was $43 \%$, and the postcourse score was $49 \%$. So, even though their participants' GLAI scores increased following the courses, there was significant room for improvement.

In light of their positive findings on genetic literacy, both Etchegary et al. (2010) and Rose et al. (2005) concede that knowledge deficits persist among their participants. Rose et 
al.'s study focuses only on a narrow range of genetic knowledge-knowledge of genetic testing for cancerwhile participants in Etchegary et al.'s study were generally highly educated and many of them had previous experience with genetic testing. Thus, as the authors of both studies imply, doubt remains about whether their conclusions translate to a broader population. Indeed, a more recent survey by Christensen et al. (2010) and Condit's (2010) literature review confirm a widespread failure to understand basic genetics.

\section{Knowledge Calibration}

We argue that the failure to accurately understand genetics is only part of the problem. Another significant component is people's failure to recognize their knowledge deficits. This is highlighted, for example, by the difference between laypersons and medical professionals. Although even physicians can be deficient in their knowledge of genetics (Hofman et al. 1993), a critical difference exists between medical professionals and laypersons in their awareness of their own knowledge state. Medical professionals are often aware of their knowledge deficits and have easier access to more knowledgeable colleagues, whereas laypersons often use genetic terms without understanding their scientific meaning (Lanie et al. 2004).

This has been referred to as the "illusion of knowing" phenomenon, in which people are overly confident about their knowledge of an area. Park (2001) argues that such people are in danger of being either complacent or dogmatic and tend to be oblivious to their vulnerability to manipulation. It may prevent people from acknowledging the need to improve their genetic literacy (Lanie et al. 2004). Therefore, attending to knowledge calibration is at least as important as focusing on consumers' genetic literacy. This need to examine knowledge calibration is acknowledged in Hogarth's (2006) triage model of financial literacy, which argues that consumers' understanding of their own limits is a key step toward properly consuming financial products.

More formally, calibration is defined as the "agreement between objective and subjective assessments of the validity of information-particularly information used in decision making" (Alba and Hutchinson 2000, p.123). Alba and Hutchinson (2000) explain that a person is well calibrated when there is a match between the level of confidence and the degree of accuracy of his or her belief. For example, a person is well calibrated if he or she is highly confident that a belief is accurate when this belief is indeed true. If, however, the person lacks confidence despite holding a correct belief or has a high level of confidence even though his or her belief is erroneous, this person is considered poorly calibrated. Therefore, determining a person's knowledge calibration requires an assessment of the person's actual knowledge, or lack thereof, and his or her level of confidence in the accuracy of that knowledge.

In defining knowledge calibration, it is important to note a related concept - namely, self-efficacy, which refers to a person's perceived ability to carry out tasks in a domain. Applied to genetic literacy, this construct reflects how much knowledge a person believes he or she has. Within the broader literature on consumer literacy, self-efficacy has received increasing attention (Contento, Randell, and Basch 2002), and it has been associated with people's choices and personal financial health (Kozup and Hogarth 2008; Wiener and Doescher 2008). However, in this stream of research, self-efficacy and literacy are usually treated separately. We go one step further and argue that, while knowledge and self-efficacy are meaningful constructs by themselves, important insights can also be gained by examining the relationship between the two. Knowledge calibration captures the gap between knowledge and self-efficacy, and as we show in the following section, its consequences are distinct from knowledge or self-efficacy alone.

\section{Consequences of Knowledge Calibration and Miscalibration}

Alba and Hutchinson (2000) argue that there are four ways that calibration can influence consumers' decision making. First, calibration can influence the amount of effort devoted to information search. An overconfident consumer will limit his or her search for further information. This is a relevant concern in the context of genetics because ignorance of one's knowledge deficit makes a quest for further information about genetic testing unlikely. In contrast, miscalibration in the direction of underconfidence may lead to oversearching for and overreliance on external information. This can be problematic when the quality of information is dubious (Javitt 2007). Moreover, extensive information search may result in information overload and greater exposure to persuasive marketing tactics.

Second, a person's confidence in the accuracy of his or her beliefs also affects decision making. Previous research has shown that higher subjective assessment of genetic knowledge correlated with a more positive attitude toward genetic testing (Etchegary et al. 2010; Morren et al. 2007). These findings point to the potential danger of knowledge miscalibration, in which consumers' decisions may be based on what they think they know about genetics rather than genuine knowledge.

Third, knowledge calibration may affect consumers' conflict resolution in the face of uncertainty. This is particularly relevant in the rapidly changing field of genetics, in which reducing uncertainty and increasing control over people's health are among the dominant reasons for undergoing genetic tests (Gooding et al. 2006). Sanderson and Wardle (2008) further point out that people's expectations of test outcomes affect their decisions whether to undergo genetic testing. If a person expects that the outcome will be bad (i.e., either the results or their reaction to the results), he or she will self-select against taking a genetic test.

However, a problem is that people's expectations may be affected by overconfidence or underconfidence in their subjective assessment of their knowledge. Miscalibration in either direction may remain concealed from the person, and it may lead to unnecessary avoidance of genetic tests or an unexpected emotional response to test results. Combined with the influence from certain emotional appeals in DTC advertising (e.g., empowerment, fear), miscalibration may lead to self-selection that is not optimal for consumer welfare. For example, a person's actual risk of developing a 
genetic disease may not closely match his or her perceived risk; thus, he or she may opt for a genetic test even though the test may be inappropriate for this person. Similarly, a person may be confident that he or she has accurately grasped the potential harms and benefits of genetic testing, when in reality he or she has not. As a result, the person may opt to purchase a DTC genetic test even though he or she is ill equipped to deal with the consequences of the decision.

The last consequence of knowledge calibration, as Alba and Hutchinson (2000) point out, is that the copresence of overconfidence and underconfidence do not create a neutral confidence or calibration level. Rather, both overconfidence and underconfidence in specific areas will play separately into how consumers process information and make decisions.

It is clear from the foregoing discussion that calibration can influence consumers' decisions at least as much as would their level of genetic literacy. Given the complex and rapidly changing nature of the field, some degree of uncertainty will persist for even the most knowledgeable consumer. Therefore, the realistic goal within this realm is the management of uncertainty rather than its elimination (Johnson, Case, and Andrews 2005; McInerny 2002). For uncertainty management to occur, however, consumers must be aware of their uncertainty. Currently, we know little about consumer uncertainty and knowledge calibration in genetics. This impedes our understanding of how knowledge calibration affects consumer decisions. Moreover, it limits sound judgment of whether business practices in this area are ethical and what kind of public policy is likely to promote effective uncertainty management and consumer welfare.

To address this problem, we present two empirical studies of consumers' genetic literacy and knowledge miscalibration. We further relate calibration to consumer demographics, educational intervention and feedback mechanisms, and consumer purchase intention and attitude toward DTC genetic tests. Although our samples were limited to college students, the University of California, Berkeley, experiment mentioned previously points to the potentially increasing relevance of DTC genetic tests for this population. Our research represents an important first step toward evaluating the current state of genetic knowledge calibration as well as the factors that may exaggerate or reduce miscalibration. In doing so, we shed light on previously concealed ethical issues related to DTC genetics, thereby raising awareness for policy makers. Our research also provides a mechanism for assessing genetic knowledge calibration, which may be used in future studies of calibration and the potential effects of miscalibration on consumer decision making.

\section{Study 1}

\section{Research Design and Sample}

To answer our research questions, we conducted an anonymous online survey of 354 college students from a large mid-Atlantic university. These students came from a variety of majors and participated in the study in exchange for extra course credit. Their age ranged from 18 to 53 years, with the median age being 21 years. Close to half the respondents $(46.9 \%)$ were male. Forty-five $(12.9 \%)$ of these stu- dents were in life sciences-related majors, such as biology and nuclear medicine, while the rest were dispersed in a variety of other majors in business, social sciences, and humanities. With these college-educated respondents, we might expect a higher level of genetic literacy than the general population. However, prior research on genetic literacy raises serious doubts about this assumption (Bowling, Huether, et al. 2008). We add to the literature by examining not only what these people know but also the gap between what they think they know and what they actually know.

The survey began by asking the respondents to rate their domain self-efficacy. This preceded the objective genetic knowledge test so that their performance on the test would not contaminate how they evaluate their self-efficacy in the genetics domain in general. Following the genetic literacy test, the respondents were asked to evaluate their test performance as an indication of their task-specific self-efficacy. Finally, they completed a few questions capturing their past training in genetics and their demographic information. The entire survey took approximately $20-30$ minutes.

\section{Measures and Variable Operationalizations}

\section{Genetic Literacy}

We adapted this measure from the GLAI, which was developed through a rigorous process by Bowling, Acra, et al. (2008). The GLAI covers six content topics: nature of the genetic material, transmission, gene expression, gene regulation, evolution, and genetics and society. Each question was presented in a multiple-choice format with five options. The multiple-choice format is commonly used in studies of financial and nutrition literacy (Burton, Biswas, and Netemeyer 1994; Moorman 1996; Perry 2008) and has been considered superior to either self-assessment or the true/ false question format (Contento, Randell, and Basch 2002; Walstad, Rebeck, and MacDonald 2010). Of the original 31 GLAI items, we omitted six that were either largely redundant with the other items or ambiguously worded, resulting in a final list of 25 questions (for a sample question, see the Appendix). ${ }^{2}$ The internal reliability of the instrument exceeded the recommended threshold of .70 $(\alpha=.77)$. The percentage of questions answered correctly functioned as an indicator of the respondents' genetic literacy.

\section{Self-Efficacy}

Following self-efficacy literature that suggests the presence of self-efficacy at different specificity levels (Bandura 1997), we included in our questionnaire both a general domain self-efficacy measure and a task-specific self-efficacy measure associated with the GLAI assessment described previously. For domain-level self-efficacy, we used four perceived consumer expertise measures from Mitchell and Dacin (1996) and adapted the items to the genetics field. We measured these items (shown in the Appendix) on an 11point semantic differential scale $(\alpha=.91)$. For task-specific self-efficacy, we followed previous practice in self-efficacy research and asked the respondents to estimate the number

2The items eliminated from the GLAI were Questions 6, 9, 14, 26, 27, and 29. 
of questions that they thought they answered correctly out of the 25 GLAI questions. Then, we asked them to rate how confident they were that they actually answered this many questions correctly on a scale from 0 to 10 . The first question pertains to self-efficacy level, whereas the second question measures self-efficacy strength (Bandura 1997).

\section{Knowledge Calibration}

Consistent with previous studies on judgment accuracy (Oskamp 1962; Schraw and Roedel 1994), we took the difference between task self-efficacy level and GLAI score for each respondent to create a knowledge calibration score. To make task self-efficacy level comparable to genetic literacy, we first translated it into a percentage figure. For example, if a respondent estimated that he or she answered 10 of the 25 questions correctly, this translates into $40 \%$ for task selfefficacy. We then calculated the difference between actual percentage of questions answered correctly and the percentage-based task self-efficacy level. The absolute value of the difference indicates the extent of miscalibration, while the sign of the difference indicates the direction of miscalibration (i.e., positive for overconfidence and negative for underconfidence).

\section{Other Measures}

In addition to objective and perceived genetic literacy measures, we included a few questions on past education, consumer attitude, and demographics. For demographics, we asked the respondents' age, gender, and their major. With regard to past education, we asked the respondents whether they had taken an undergraduate-level biology course and an undergraduate-level genetics course before. We also measured their attitude toward DTC genetic tests and their intention to purchase a DTC genetic test. We assessed attitude with the question. "How do you feel about manufacturers selling genetic tests directly to consumers?" which was measured on an eight-point scale anchored at "very negatively/ very positively." Intention was measured by the question "How likely are you to purchase a genetic test directly from the manufacturer of such tests?" It was also measured on an eight-point scale anchored at "very unlikely/very likely."

\section{Results}

\section{Genetic Literacy and Knowledge Calibration}

Confirming previous studies, our results revealed a low level of genetic literacy. The respondents' GLAI score ranged from $4 \%$ to $100 \%$, and the average was $43.29 \%$. In general, this is comparable to the scores reported by the original GLAI developers (Bowling, Acra et al. 2008). Men performed marginally lower on the GLAI test than women $(\mathrm{M}=41.3 \%$ vs. $45 \% ; \mathrm{t}=-1.88, p=.06)$. Age correlated significantly with GLAI score, with older students more literate than younger students $(\mathrm{r}=.14, p=.009)$.

What we are most interested in, however, is not just how much our respondents know about genetics but also how much they think they know compared with what they actually know. We were surprised by what we found. In contrast to the typical findings of overconfidence in consumption and other task domains (Alba and Hutchinson 2000), we saw a general tendency toward underconfidence when it comes to genetic knowledge. When asked how many questions they thought they answered correctly, the respondents reported an average of $36.92 \%$, significantly lower than their average actual performance of $43.29 \%(\mathrm{t}=5.63, p<$ $.001)$. This underconfidence is further supported by the low domain self-efficacy respondents reported at the beginning of the survey, before they answered the GLAI questions. The average domain self-efficacy level was only 3.91 on an 11 -point scale. Moreover, respondents reported only a moderate level of task self-efficacy strength $(M=5.94$ out of 10). It appears that when it comes to the complex field of genetics, in general, people are not very confident in their knowledge.

We looked further into knowledge calibration by examining if there was any gender or age difference. Recall that male students performed marginally worse on the GLAI than female students. When we examined the knowledge calibration score for each gender group, both groups showed significant miscalibration. However, male students showed somewhat better calibration than female students, and their estimates were off by $14.73 \%$ compared with $18.73 \%$ for female students $(\mathrm{t}=-2.71, p=.007)$. Examining the direction of the miscalibration suggests that male students were equally likely to be underconfident as overconfident $(\mathrm{M}=-1.81 \% ; \mathrm{t}=1.19, p=$ not significant [n.s.]). In contrast, female students were significantly more likely to be underconfident $(\mathrm{M}=-10.12 \% ; \mathrm{t}=-6.55, p<.001)$, even though they performed better on the actual knowledge test. Age correlated positively with the extent of miscalibration $(\mathrm{r}=.12, p=.02)$, meaning that older students were more likely to be miscalibrated than younger students. With regard to the direction of the miscalibration, older students were more likely to underestimate than younger students $(r=$ $-.17, p=.002)$.

\section{"Experts" Versus Laypersons}

Because life sciences students were likely to have received more extensive education related to genetics, we consider these students relative "experts" in our sample. Although they only accounted for $12.9 \%$ of our sample, their absolute size of 45 was sufficiently large for us to compare their performance and calibration with the layperson sample of the other majors. Consistent with our conjecture of their superior expertise, life sciences students performed significantly better, although still far from satisfactory, on the GLAI than the other students $(\mathrm{M}=53.96 \%$ vs. $41.86 \%$; $\mathrm{t}=4.21, p<$ $.001)$. Furthermore, life sciences students perceived themselves as more capable in the domain of genetics $(\mathrm{M}=4.43$ vs. $3.84 ; \mathrm{t}=2.05, p=.04)$. When asked to estimate specifically how well they did on the GLAI, they reported better performance than non-life sciences students $(M=47.27 \%$ vs. $35.55 \%$; $\mathrm{t}=3.46, p=.001)$, but task self-efficacy strength did not differ significantly between the two groups.

Prior research has produced ambiguous findings with regard to the relationship between expertise and the accuracy of knowledge calibration (Alba and Hutchinson 2000). For our sample, although life sciences students performed better on the GLAI test and, in general, perceived themselves as more competent in the genetics domain, they fared 
no better on knowledge calibration than the rest of the respondents $(\mathrm{M}=18.09 \%$ vs. $16.60 \% ; \mathrm{t}=.68, p=$ n.s. $)$. They also did not differ in the direction of miscalibration and were just as likely to be underconfident as their non-life sciences counterparts $(\mathrm{M}=-6.46 \%$ vs. $-6.14 \% ; \mathrm{t}=-.09, p=$ n.s.). This lack of better calibration may have stemmed from the possibility that, although these life sciences students received more education in the life sciences field, their learning was very general and did not provide sufficient and instantaneous feedback on their genetics-specific knowledge. According to Alba and Hutchinson (2000), such feedback is often a prerequisite to improved calibration.

\section{Value of Educational Intervention}

Given the complexity of genetic science, it has often been suggested that the public needs to be better educated to make informed decisions about DTC genetic tests (e.g., Liu and Pearson 2008). To understand the potential value of such educational intervention, we examined the respondents' GLAI score and self-efficacy judgments with respect to relevant education they had received in the past. Specifically, we asked the respondents whether they had taken a college-level biology course or a college-level genetics course. Constraining these educational measures to the college level ensures that the education was received within a recent enough time frame to benefit the respondents. Not surprisingly, a majority $(82.22 \%)$ of the life sciences students had previously taken a biology course. As a result of general education requirements, many $(40.46 \%)$ of the nonlife sciences students had also taken the course. However, only 13 students from our entire sample had previously taken a genetics course. Given the overwhelming imbalance, we dropped this variable and instead focused our analysis on the biology course.

Because of the significantly higher likelihood of taking a biology course for life-sciences students $\left(\chi^{2}=27.54, p<\right.$ $.001)$, we analyzed the effect of the biology class using an analysis of variance (ANOVA), including major as a covariate to control for the possibility that other courses life sciences students had taken within their major may also affect their genetic knowledge and calibration. Our results indicate that taking a biology course significantly enhances a person's knowledge in genetics, with the average GLAI score being $48.9 \%$ for those who had taken the course versus $38.5 \%$ for those who had not $(\mathrm{F}=845.72, p<.001)$. However, even with the course, the GLAI score was far from satisfactory. Having taken a biology course also increased domain self-efficacy $(\mathrm{M}=4.18$ vs. $3.68 ; \mathrm{F}=$ $682.32, p<.001)$, task self-efficacy level $(\mathrm{M}=40.6 \%$ vs. $33.8 \% ; \mathrm{F}=441.42, p<.001)$, and task self-efficacy strength $(\mathrm{M}=6.19$ vs. $5.72 ; \mathrm{F}=721.15, p<.001)$.

Notably, students who had taken a biology course actually reported a larger extent of miscalibration than those who had not $(\mathrm{M}=17.6 \%$ vs. $16.1 \% ; \mathrm{F}=224.09, p<.001)$. Examining the direction of the miscalibration suggests that, on average, those who had taken a biology course were more likely to feel underconfident than students who had not previously taken the course $(\mathrm{M}=-8.1 \%$ vs. $-4.7 \% ; \mathrm{F}=14.72$, $p<.001)$. Putting these results together, it appears that taking a biology course increased students' actual knowledge more than their confidence level. It is possible that the course made them realize the complexity of genetic science and subsequently their knowledge deficiency in this area.

\section{Consumer Reaction to DTC Genetic Tests}

As an auxiliary to our main research question, we also asked respondents how they felt toward DTC genetic tests and how likely they were to purchase such tests. Attitude toward DTC genetic tests ranged from 1 to 8 , with a fairly low mean of 3.64 (on an eight-point scale). Average purchase intention was even lower at 2.56. We note that this intention could have been lower for our sample than for the general population because of students' relatively low income and the perceived high cost of such tests. On average, male students reported a more positive attitude toward DTC genetic tests than female students $(\mathrm{M}=3.89$ vs. 3.42; $\mathrm{t}=2.41, p=.02)$. They also had a higher intention to purchase such tests $(\mathrm{M}=2.76$ vs. $2.39 ; \mathrm{t}=2.11, p=.04)$. Life sciences students reported attitude and purchase intention similar to the other majors.

When examining the effect of knowledge calibration on attitude and purchase intention, we did not find a significant relationship between extent of miscalibration and attitude or purchase intention. However, the direction of miscalibration had a significant impact on purchase intention, with overconfidence leading to a higher likelihood of purchase than underconfidence $(\mathrm{r}=.15, p=.005)$. This is consistent with previous findings reported in Etchegary et al. (2010). Perhaps because some consumers are overconfident about their genetic knowledge, they are more likely to overestimate the benefits they can receive from DTC genetic tests and therefore are more likely to purchase such tests.

To understand the relative impact of actual knowledge and perceived self-efficacy on purchase intention, we regressed both attitude and purchase intention on the GLAI score and domain self-efficacy. We did not include task efficacy because of high collinearity with domain self-efficacy. ${ }^{3}$ Our results suggest that both attitude $(\beta=.18 ; \mathrm{t}=3.27, p=$ $.001)$ and purchase intention $(\beta=.27 ; \mathrm{t}=5.04, p<.001)$ were predominantly driven by domain self-efficacy, whereas actual genetic knowledge did not have a significant impact on either attitude or purchase intention. This finding is alarming because it points to a danger of purchasing DTC genetic tests purely out of perceived expertise level even in the absence of sufficient knowledge to make truly informed decisions.

To determine whether the different groups of students based their attitude and purchase intention on different things, we ran the same regressions separately for life sciences students and the rest of the sample. For non-life sciences students, the pattern of results remained similar to those reported for the entire sample. However, for life sciences students, a different pattern of results emerged. While domain self-efficacy also had a significant positive impact on purchase intention $(\beta=.68 ; \mathrm{t}=4.78, p<.001)$, actual genetic knowledge (i.e., GLAI score) showed a marginally significant negative effect $(\beta=-.27 ; \mathrm{t}=-1.91, p=.06)$. In

\footnotetext{
${ }^{3}$ Running the regressions with task self-efficacy instead of domain selfefficacy yielded similar results.
} 
other words, the genetic knowledge these life sciences students possessed acted as a counterbalancing force that curbed their enthusiasm toward DTC genetic tests, possibly due to their skepticism about the value of such tests. However, this was not the case for attitude toward DTC genetic tests, which remained driven only by domain self-efficacy. We also ran the regression separately by gender and by educational intervention (i.e., biology course), but we found no significant difference between these groups. We show the results for all these regressions in Table 1.

\section{Study 2}

\section{Overview}

Study 1 explored how consumer demographics and past education are related to knowledge calibration and how genetic literacy and knowledge calibration affect consumers' attitude and intention toward genetic tests. For public policy purposes, however, it is desirable to take these findings further and identify what can be done to increase consumer genetic literacy and, at the same time, bridge knowledge calibration gap. Study 1 partially addressed this by considering the effect of college major and an undergraduate-level biology class, but these are rather crude measures of educational intervention. The biology class does not focus solely on genetic knowledge and may have occurred in a relatively distant past. Furthermore, it is unreasonable to assume that every consumer can feasibly undertake such a multiweek college-level training to adequately deal with genetic test consumption.

For these reasons, we conducted another study to further investigate the impact of education and feedback mechanisms on consumers' genetic knowledge and calibration. Replicating what most consumers are likely to encounter on the Internet, we created a brief four-part genetics online educational module (for a screenshot of part of the module, see Figure 1) excerpted from the Genetics Home Reference Handbook by the National Institute of Health (http://ghr. nlm.nih.gov/handbook). Our choice of an online delivery format is partially driven by prior consumer literacy research showing that website-based educational materials are effective in achieving positive learning outcomes (Silk et al. 2008). The four parts of the educational module covered the topics of basic genetic concepts, inheritance, genetic mutations, and genetic tests, respectively. While these topics are fairly basic, we believe that they represent an accessible entry point in educating the general public about genetic science and are relatively easy to implement on a large scale. Our purpose was to understand how the availability of such an educational module may affect consumers' genetic literacy and knowledge calibration.

Besides the availability of educational materials, how the education process is designed can also influence learning outcomes. In this study, we further examine the relative effectiveness of various feedback mechanisms in conjunction with the educational module. Although feedback is traditionally an important component of education, recent comprehensive reviews of this field suggest that the effect of feedback is far from straightforward and thus warrants further examination (Hattie and Timperley 2007; Shute 2008). Moreover, most studies in this area have examined the effect of feedback on knowledge acquisition, and little is known about how feedback affects knowledge calibration. Therefore, our study extends this line of research by investigating the effectiveness of feedback mechanisms on both knowledge acquisition and calibration. In doing so, we also respond to the call for more experiment-based research to study the relative effectiveness of different educational designs in enhancing consumer literacy (Fox, Bartholomae, and Lee 2005).

\section{Study Design}

A total of 181 undergraduate business students participated in the study in exchange for extra course credit. Of the participants, $64.6 \%$ were female, and $35.4 \%$ were male. The median age was 22 years. The procedure for the study was similar to that of Study 1, except that we inserted the educational module and feedback section before the GLAI ques-

Table 1. Determinants of Attitude and Purchase Intention

\begin{tabular}{|c|c|c|c|c|c|c|}
\hline \multirow[b]{2}{*}{ Groups } & \multicolumn{3}{|c|}{ Attitude } & \multicolumn{3}{|c|}{ Purchase Intention } \\
\hline & $\begin{array}{c}\text { Genetic } \\
\text { Knowledge }\end{array}$ & Self-Efficacy & $\mathbf{R}^{2}$ & $\begin{array}{c}\text { Genetic } \\
\text { Knowledge }\end{array}$ & Self-Efficacy & $\mathbf{R}^{2}$ \\
\hline \multicolumn{7}{|l|}{ By Gender } \\
\hline Male & $.06^{\text {n.s. }}$ & $.18^{*}$ & .20 & $-.06^{\mathrm{n} . \mathrm{s}}$ & $.33 * * *$ & .32 \\
\hline Female & $.10^{\text {n.s. }}$ & $.16^{*}$ & .20 & $-.05^{\text {n.s. }}$ & $.19 * *$ & .19 \\
\hline \multicolumn{7}{|l|}{ By Major } \\
\hline Life sciences & $-.03^{\text {n.s. }}$ & $.53 * * *$ & .52 & $-.27^{*}$ & $.68^{* * *}$ & .60 \\
\hline Other majors & .07 n.s. & $.12 *$ & .15 & $-.04^{\text {n.s. }}$ & $.22 * * *$ & .21 \\
\hline \multicolumn{7}{|l|}{ By Educational Intervention } \\
\hline Taken a biology course & $.12^{\text {n.s. }}$ & $.24 * *$ & .17 & -.09 n.s. & $.32 * * *$ & .31 \\
\hline Not taken a biology course & $.08^{\text {n.s. }}$ & $.14 *$ & .29 & $.02^{\text {n.s. }}$ & $.25 * * *$ & .25 \\
\hline $\begin{array}{l}* p<.1 \\
* * p<.01 \\
* * * p \leq .001 . \\
\text { Notes: The numbers in the table ar }\end{array}$ & egression co & ents. $n . s .=$ not & & & & \\
\hline
\end{tabular}


Figure 1. Screenshot of the Online Genetics Educational Module

Module 1: Basic Concepts

- DNA (deoxyribonucleic acid) is the hereditary material found in the cells of humans and nearly all other organisms. The DNA molecule consists of approximately 3 billion base pairs that form a double helix.

- A gene is a sequence of DNA that codes for a specific function, usually a protein.

- Humans have approximately 20,000-25,000 genes, each of which varies in size.

- The DNA molecule is packaged inside chromosomes, which are transmitted from parents to their offspring. Chromosomes are composed of DNA tightly wound around proteins that give chromosomes their structure.

- Humans have 23 pairs of chromosomes, for a total of $\mathbf{4 6}$ chromosomes. 22 pairs of chromosomes are the same in both males and females, but the 23rd pair differs with females having two $X$-chromosomes and the male having one $\mathbf{X}$ and one $Y$-chromosome.

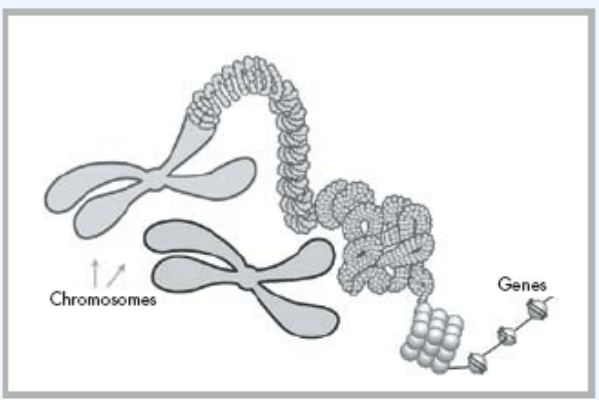

Image Source: The Australasian Genetics Resource Book

tions. This "intervention" enabled us to measure the impact of education and feedback as reflected in the respondents' GLAI performance and task self-efficacy evaluations.

Each participant was randomly assigned to one of six experimental conditions. Four of these conditions featured a 2 (instant vs. delayed feedback) $\times 2$ (detailed vs. brief feedback) factorial design. We focused on these two factors because timing and content of feedback have been shown to affect the effectiveness of feedback (Kluger and DeNisi 1996). In the instant feedback condition, participants answered three true/false questions immediately after each part of the educational module and were given feedback on whether they answered the questions correctly. In the delayed feedback condition, participants answered all true/false questions only after all four parts of the module have been completed. For detailed feedback, participants were told whether they answered a question correctly and why the statement was right or wrong. In the brief feedback condition, participants were told only whether their answers were correct but not why.

In the fifth condition, participants went through the educational materials but there were no true/false feedback questions and no learning feedback. This enabled us to examine the general effect of feedback. We also added a sixth condition as the control group, in which participants answered the rest of the questionnaire without going through the educational module at all. In all six conditions, participants first reported their domain self-efficacy with regard to genetics. Then, depending on the experimental condition, participants either went through the four-part educational module (with or without feedback) and then took the GLAI assessment or went directly to the GLAI for those in the control group. At the end of the questionnaire, all participants estimated their performance on the GLAI and then answered some general family history and demographics questions. The whole study was administered over the Internet.

\section{Measures}

The measures used in Study 2 were exactly the same as the first study except the GLAI questions. Instead of the 25question version of the GLAI we used in Study 1, we further condensed the GLAI into 16 questions $(\alpha=.72) .{ }^{4} \mathrm{We}$ did this for two reasons: (1) The experiment with the educational module was already long, and we did not want to cause fatigue, which would have affected the quality of responses, and (2) because the educational module addressed only selected topics, we considered it more appropriate to use questions in the GLAI that are related to these topics. Consequently, we removed 8 questions that were not related to the four topics covered by the educational module.

${ }^{4}$ For Study 2, the items further eliminated from the GLAI were Questions $3,4,5,7,11,17,18,24$, and 31 . 
In the demographics section, we added one question on family health history. The question asked the participants whether they or someone in their family (siblings, parents, and grandparents) ever had 1 of 11 health conditions, such as heart disease, cancer, diabetes, and genetic disease. Because genetic disease represents a broader set of conditions that the participants may or may not be aware of, we offered several well-known examples (e.g., cystic fibrosis, sickle-cell disease) along with that option to help clarify its scope. We used the total number of health conditions a participant selected to gauge his or her family health history, which could affect the participant's vulnerability to hereditary conditions and, subsequently, their interest in genetic tests. The number of health conditions selected ranged between 0 and 9 , and the median was 3 .

\section{Results}

\section{Impact of Education}

Figure 2 shows the GLAI performance and knowledge calibration gap for the six experimental conditions. To examine the general impact of the educational materials on genetic knowledge, we conducted an ANOVA with the percentage of correct GLAI answers as the dependent variable and the

Figure 2. GLAI Performance and Knowledge Calibration Across Study 2 Participants
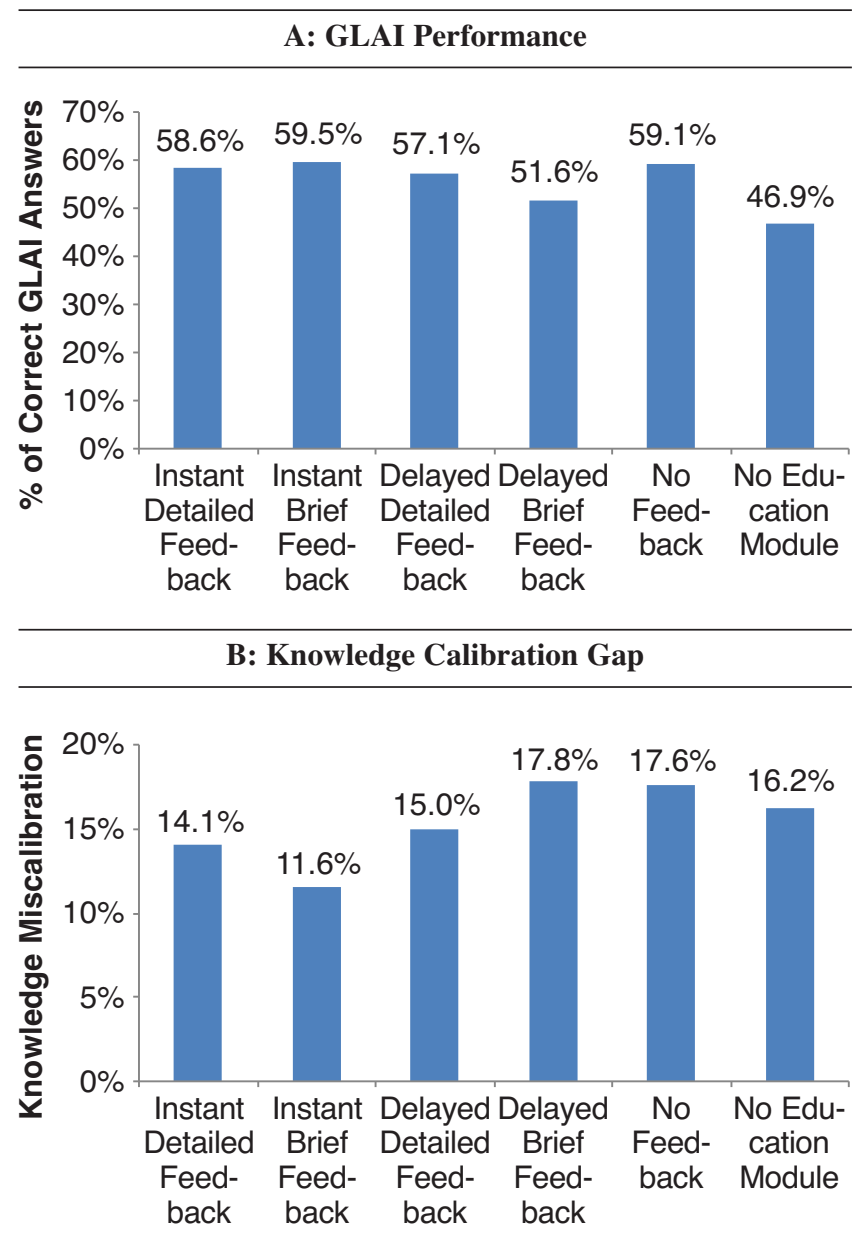

presence/absence of educational module as the independent variables. To control for the idiosyncrasies that may arise from family history, we included it as a covariate. The results showed that participants who were exposed to the educational module answered a significantly greater portion of the GLAI questions correctly than those who did not receive the educational module $(\mathrm{M}=57.4 \%$ vs. $46.9 \% ; \mathrm{F}=$ $319.90, p=.005)$. Although the performance was fairly low even with the educational module, the module improved performance by more than $10 \%$, which is impressive given the brevity of the module. Family history did not have a significant effect on GLAI performance. 5

From the preceding results, it appears that education can increase genetic knowledge. However, for knowledge calibration, the key question is whether the increase in knowledge outpaces or falls behind increase in consumers' confidence levels. To answer this question, as in Study 1, we calculated the calibration score as the absolute difference between actual and participant-estimated GLAI performance and used it as the dependent variable in the ANOVA. The results show that the presence of educational materials significantly decreased knowledge miscalibration, with participants in the education condition reporting a significantly lower miscalibration than those in the no-education condition $(\mathrm{M}=14.9 \%$ vs. $16.2 \% ; \mathrm{F}=28.8, p<.001)$.

Looking further at the direction of the miscalibration, our results suggest that having been exposed to the educational module corrected the prevalent underconfidence toward a more neutral and slightly positive position $(\mathrm{M}=-7.1 \%$ vs. $2.5 \% ; \mathrm{F}=4.28, p=.015)$. Together, this represents an opposite effect to what we found in Study 1, in which we found that taking a biology class exacerbated participants' miscalibration and more underconfidence. Recall, however, that our educational module was more focused on genetics, and it can be reasonably argued that it was much less challenging to learn than a college-level biology class. As a result, Study 2 participants may have been better able to absorb the materials and calibrate their beliefs about their knowledge levels. This suggests that the content and format of educational materials matter to learning outcomes and knowledge calibration. For the purpose of educating the general public about genetics, it may be more beneficial to use concise, simple-to-understand content to avoid cognitively overloading the learner and to ensure optimal learning outcomes.

\section{Impact of Feedback}

We conducted a similar set of analyses to understand the impact of feedback on knowledge acquisition and calibration. Because participants in the control group did not receive any educational material or feedback, we excluded them from this analysis. The analysis showed that having a feedback mechanism in place did not have a significant effect on GLAI performance ( $\mathrm{M}=59.1 \%$ for participants in the no-feedback condition and $57.1 \%$ for those in the feedback conditions; $\mathrm{F}<1$ ). However, feedback significantly reduced

\footnotetext{
5Unless otherwise noted, we included family history as a covariate in all the analyses conducted in this section. We found no significant effect for the variable in any of the analyses. This does not mean that family history does not affect consumer decision making about genetic tests. Rather, it is likely the result of our choice of constructs and measures.
} 
knowledge miscalibration $(\mathrm{F}=27.67, p<.001)$, extending previous research finding that feedback can reduce uncertainty a learner feels about his or her performance (Ashford, Blatt, and VandeWalle 2003). The average extent of knowledge miscalibration was $17.6 \%$ for those who did not receive feedback and $14.3 \%$ for those who received feedback. Furthermore, there was no significant effect of feedback on the direction of miscalibration $(F<1)$. This suggests that having a feedback mechanism in place is equally likely to correct underconfidence and overconfidence.

To understand the relative effectiveness of specific feedback mechanisms, we examined the four experimental groups that received various combinations of feedback timing and feedback details. We did this by running ANOVAs with the two feedback factors as the independent variables. Our results show that participants who were given instantaneous assessment questions and feedback performed marginally better than those who were given delayed feedback $(\mathrm{M}=59.0 \%$ vs. $54.3 \% ; \mathrm{F}=2.75, p=.10)$. This is consistent with previous research that shows immediate feedback to be more effective when the type of feedback given is specifically related to the task at hand (Hattie and Timperley 2007). Under such conditions, instant feedback leads to more efficient retention of learned materials (Shute 2008). No other effect was significant for GLAI performance.

For knowledge calibration, neither feedback timing nor feedback detail had a significant main effect. However, there was a significant interaction between the two feedback factors $(\mathrm{F}=4.50, p=.036)$. As Figure 3 shows, when detailed feedback was offered, immediacy of feedback did not have a significant effect on knowledge calibration $(\mathrm{M}=$ $15.0 \%$ for delayed feedback and $14.1 \%$ for instant feedback). However, when only brief feedback was offered, instant feedback was more effective in reducing knowledge miscalibration $(\mathrm{M}=11.6 \%)$ than delayed feedback $(\mathrm{M}=$ $17.8 \% ; \mathrm{t}=2.09, p=.04)$. For the direction of knowledge miscalibration, none of the feedback mechanisms made a significant difference.

As Figure 2, Panel A, shows, among the four conditions that offered some form of feedback (the left four bars), delayed brief feedback generated the worst learning out-

\section{Figure 3. Interaction Between Feedback Timing and} Feedback Detail on Knowledge Calibration

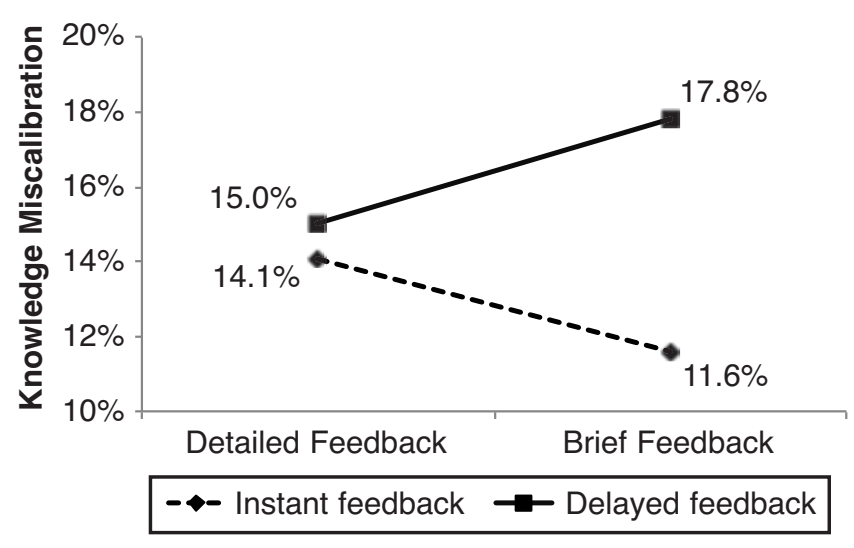

comes, with an average GLAI score of $51.6 \%$. It also resulted in the largest calibration gap of $17.8 \%$, as Figure 2, Panel B, shows. Participants in this condition did as poorly on knowledge calibration as those who received no feedback at all $(\mathrm{M}=17.6 \%)$. As Figure 2, Panel B, shows, the largest difference existed between the delayed brief feedback and the instant brief feedback conditions $(\mathrm{M}=17.8 \%$ vs. 11.6\%). This latter group had the opportunity to absorb the information in each part before moving on to the next and therefore was better able to adjust their calibration. In contrast, participants in the delayed brief feedback condition received feedback only after they had gone through all four parts of the educational module and, as a result, may have experienced deterioration in retention. Although participants who received delayed but detailed feedback faced the same disadvantage, it is likely that further instruction provided by detailed feedback at least partially compensated for the delay in feedback. This may explain why these participants performed better in both GLAI ( $\mathrm{M}=57.1 \%$; see Figure 2, Panel A) and knowledge calibration $(\mathrm{M}=$ $15 \%$; see Figure 2, Panel B) than those in the delayed brief feedback condition.

\section{General Discussion and Public Policy Implications}

\section{Summary}

Genetic tests are unique products in that they require complex scientific knowledge to understand and use properly. With the increasing availability of genetic tests marketed directly to consumers, serious concerns arise as to whether average consumers possess the knowledge and tools to make sound decisions about such products. Echoing such concerns, this research empirically examined consumers' genetic literacy levels and their awareness of their own knowledge state. Our findings confirmed a generally low level of genetic literacy among our research samples. Across the two studies, the participants answered an average of only $43.29 \%$ and $56.15 \%$ of the questions correctly, respectively. Although respondents in the life sciences fields from Study 1 scored significantly higher than the rest of the respondents $(53.96 \%$ vs. $41.86 \%)$, their performance was far from satisfactory either.

While the low genetic literacy level we found is not surprising in light of similar findings from previous research, the current research extends the literature in two significant ways. First, we examined not only genetic literacy but also consumers' knowledge calibration in the genetics field. Consumer research suggests that, besides actual knowledge about a product or product category, subjective beliefs about one's knowledge can also have a significant impact on consumers' information search, information processing, and decision-making processes. Previous studies in this area show a prevalence of overconfidence among consumers (Alba and Hutchinson 2000; Park 2001). In the area of financial literacy, for example, Perry (2008) finds that most consumers overestimated their credit score while only a handful underestimated it. Study 1 provides a contrary scenario, in which consumers were miscalibrated in the direction of underconfidence. While overconfidence in 
other areas may be due to consumers' inability to assess the difficulty of a task (Perry 2008), we surmise that our finding of underconfidence could be caused by a widely held belief that genetic science is extremely complex, thus contributing to an overestimation of task difficulty. The underconfidence observed in our research samples suggests that researchers and policy makers should not take overconfidence for granted. Instead, they should study the potential impact of both overconfidence and underconfidence when it comes to consumption of genetic tests.

Second, we studied specific educational intervention and feedback mechanisms aimed at both improving genetic literacy and bridging calibration gap. Using a brief four-part online educational module, Study 2 shows that educational intervention improved both genetic literacy and calibration, though the magnitude of improvement depended on the availability and type of feedback mechanisms used. For genetic literacy, instant feedback led to better GLAI performance than delayed feedback ( $59 \%$ vs. $54.3 \%)$. In terms of knowledge calibration, the mere presence of feedback reduced knowledge miscalibration. Furthermore, there was a significant interaction between feedback timing and feedback detail. Immediacy of feedback improved knowledge calibration only when brief feedback was offered. When detailed feedback was offered, immediacy of feedback did not make a difference in knowledge calibration.

A disturbing finding from our study was the discovery about what really drives consumer attitude and purchase intention in the realm of DTC genetic tests. Instead of relying on actual knowledge, the respondents' attitude and purchase intention were driven predominantly by how much they thought they knew, affirming the need to study knowledge calibration. Although this subjective knowledge effect was somewhat mitigated for respondents in the life sciences fields, these consumers were still only marginally affected by their actual knowledge of genetic science when it came to their likelihood of buying a DTC genetic test. For them, perceived knowledge level in the form of domain self-efficacy remains the more important driver, as with the rest of the sample.

\section{Public Policy Implications}

Our study represents a first step toward understanding not only consumers' actual knowledge of genetics but also their subjective assessment of their own knowledge levels. Combined with previous research on the significant influence of knowledge calibration on consumer behavior, our research findings point to a need to consider the relationship between objective knowledge and subjective knowledge when creating public policy related to DTC genetic testing. In our earlier section titled "Consequences of Knowledge Calibration and Miscalibration," we pointed to differing problems arising depending on the direction of miscalibration. Although it is preferable for people to be well calibrated, we believe that people who are miscalibrated in the direction of underconfidence are better situated than those who are overconfident. Our reason for holding this view is that those who know more than they believe they know are at least aware of limitations on the scope of their knowledge and therefore are less likely to proceed recklessly into unfa- miliar territory. This cautiousness better protects consumer interests and public welfare. Nevertheless, being well calibrated is preferable, and our results in Study 2 provide preliminary evidence that at least one type of educational intervention can help bridge existing calibration gaps. In light of our findings, we make several specific policy recommendations about consumer genetics education and the regulation of information quality and delivery in this area.

\section{Genetics Education Design}

Researchers have issued numerous calls for more public education in genetic sciences. Past recommendations have included public education campaigns (Liu and Pearson 2008) and a larger genetic science component in K-12 education (American Society of Human Genetics 2004). Here, we argue that how education is delivered is as critical as expanding its dissemination. This emphasis on proper educational design has been pointed out by previous financial literacy research (Fox, Bartholomae, and Lee 2005; Walstad, Rebeck, and MacDonald 2010). We echo this sentiment while adding that public education should improve not only consumers' knowledge about genetic tests but also the accuracy of their knowledge calibration, the latter of which has received limited attention in consumer literacy and public policy discussions. If not properly implemented, some educational efforts may disproportionally inflate consumers' perceived knowledge level and consequently lead to increased consumption of DTC genetic tests regardless of the actual benefits or harms of using such tests. It is critical, therefore, to build knowledge calibration measurements into the evaluation of a public education program, beyond traditional assessment such as knowledge gain.

Our research further points to strategies for creating effective educational interventions. For example, in Study 2 , we demonstrate the importance of offering an appropriate feedback mechanism in the educational process to improve both learning and knowledge calibration. Previous calibration literature has suggested that instantaneous feedback during the learning process enhances the accuracy of consumers' knowledge calibration (Alba and Hutchinson 2000). The results of Study 2 provide further support for this claim. Thus, to the extent possible, public education in this area should integrate a timely feedback mechanism to assess the accuracy of consumers' knowledge. For example, on genetic education websites, a quiz such as the one we used in Study 2 can be offered, and the format of the quiz can be made fun or interesting to encourage consumer usage. Incentives, such as small rewards (e.g., game points), may also be provided to motivate the use of such feedback mechanisms. On DTC genetic companies' websites, such quizzes can further help identify highly deficient consumers who can then be advised to consult healthcare professionals before a purchase decision is made.

In addition to formal or more traditional educational interventions, the findings in Study 2 show the promise of informal education that can be delivered easily in an online environment. Although the online educational module used in our research was fairly brief, it led to significant improvement in both genetic literacy and knowledge calibration. This is consistent with a past finding that education 
of a longer duration does not necessarily contribute to greater learning (Fox, Bartholomae, and Lee 2005). Together with previous research findings on consumer education in other product categories, our research points to the potential for making genetic education more accessible to the general public through less conventional approaches such as documentaries, television dramas or sitcoms (Spader et al. 2009), interactive games (Silk et al. 2008), and museum exhibits. Addressing such an unconventional measure, Spader et al. (2009) suggest that using television dramas to provide financial education not only educates but also generates awareness of the need for financial education, thereby potentially increasing the reach and effectiveness of more formal educational means.

Whether formal or informal education is used, it is important to recognize the need to target educational interventions so that they work well with the characteristics of the intended audience, including beliefs, preferences, language, culture, area-specific knowledge, self-efficacy, and, for some interventions, computer literacy and access (Davis, Gazmararian, and Kennen 2006; Spader et al. 2009). This more customized approach is supported, for example, by Silk et al.'s (2008) study showing that the educational impact of a computer game aimed at increasing nutrition literacy is influenced by people's preconceived notions about the purpose of games. Likewise, Huston (2010, p. 310) concludes that "financial literacy education ... can and should be tailored to suit different demographics, life stages, and learning styles - not as a one-size-fitsall approach." Therefore, the key is to offer a diverse set of educational measures to accommodate different learning styles and literacy levels.

\section{Oversight and Regulation of Information Quality and Marketing Practices}

Because deficits in science and health literacy have the potential to create problems in myriad facets of life, it is a problem worth resolving in its own right. However, when we consider genetic literacy deficits and knowledge miscalibration in the context of online DTC marketing of genetic tests, the need for oversight and regulation to protect consumer welfare becomes even clearer. In criticizing the Pearson v. Shalala (1999) decision, which rejected the Food and Drug Administration's argument about misleading health claims on nutrition labels, Vladeck (2000) points out the vulnerability of even well-informed consumers to unconfirmed scientific data delivered through sales pitches. Prospective consumers of DTC genetic tests are no less vulnerable. Consequently, along with ensuring the effective delivery of genetics education so that both genetic literacy and knowledge calibration can be improved, we also recommend that public policy makers pay close attention to the quality of available information.

Oversight is especially important given our finding of consumer underconfidence in the genetics domain. While underconfidence may not be as undesirable as potentially reckless behavior resulting from overconfidence, one consequence of underconfidence is that these consumers may be more likely to turn to external sources for information (Alba and Hutchinson 2000) and, as a result, amplify the influence of external information on their judgment. Although increased information search is not bad per se, it increases consumers' vulnerability to inaccurate or misleading information and the possibility of information overload, both of which can reduce decision quality (Jacoby, Speller, and Kohn 1974). Underconfident consumers may also take another route: They might consider the task too complex and opt out of the decision-making process altogether, compelling others (e.g., physicians, family members) to decide for them (Rotfeld 2008). This could result in their being deprived of potentially useful health-related information.

As an important channel for delivering genetic information to consumers, it would be ideal if DTC genetic test marketers were to closely examine the accuracy of the information that they provide to consumers and to support their claims with reliable scientific evidence. There is, however, healthy skepticism about whether such a standard will be followed by a company trying to sell genetic tests DTC, especially if it runs the risk of diminishing sales and, therefore, profits (Davis, Gazmararian, and Kennen 2006). In this regard, Kozup and Hogarth's (2008) observation regarding the role of public policy in promoting consumers' financial security is applicable to the promotion of sound consumer decisions regarding genetic testing. It may be necessary for regulatory agencies such as the Federal Trade Commission and trade associations to intervene in the educational process to ensure the delivery of good quality information to consumers. Similar to the Nutrition Labeling and Education Act (Public Law 101-535), which has been found to improve information and marketing practices among food manufacturers (Caswell et al. 2003), such third-party oversight may provide genetic test marketers the necessary motivation to comply with higher information quality standards. Despite budget limitations, we hope that this study's data and recommendations will prompt the Federal Trade Commission and other watchdog organizations to give greater priority to addressing exaggerated or fraudulent claims made by those marketing genetic tests DTC.

In addition to ensuring the accuracy and comprehensiveness of information, genetic testing companies, the Federal Trade Commission, and public policy makers should examine the use of specific marketing tactics that may worsen consumers' knowledge miscalibration and low genetic literacy. For example, consider one of the most prevalent marketing tactics - the empowerment appeal-observed in online DTC marketing practices (Liu and Pearson 2008). Although such a confidence-boosting appeal could counteract problematic effects associated with the tendency toward underconfidence, the use of such an appeal runs the risk of raising a person's confidence level so that he or she will simply be miscalibrated in the opposite direction. Even if there were not a complete reversal of the direction of miscalibration, our findings of a positive correlation between self-efficacy and both attitude and purchase intention suggest that companies should exercise restraint in their use of empowerment appeals or other emotional appeals designed to affect people's confidence levels. Here, the role of public policy will be to ensure informed and ethically sound use of DTC marketing of genetic tests and/or to encourage industry self-regulation and oversight (e.g., through a trade association) in the use of marketing information and tactics. 


\section{Effective and Efficient Information Delivery}

Delivering educational materials to the public can be a costly process (Silk et al. 2008). Unlike financial education, which receives ample funding from both public and private institutions (Fox, Bartholomae, and Lee 2005), genetics education does not enjoy the same resource abundance. As a result, it is important to deliver information to consumers in a cost-effective and easily accessible way. A relatively simple first step toward improving consumers' genetic literacy and knowledge calibration would be to better publicize the availability of existing resources, such as the National Library of Medicine's Genetics Home Reference, the genetics education section of the Department of Health and Human Services' HealthFinder.Gov website, and the National Institutes of Health's National Human Genome Research Institute website. In addition, previous research on nutrition literacy suggests that effective and accessible information presentation can bridge the disadvantage created by consumer knowledge gap (Moorman 1996). Therefore, creators of websites should work to make the search and use of information easier for consumers. One stride in this direction is the Office of Disease Prevention and Health Promotion's guide to facilitate the creation of user-friendly health websites (see U.S. Department of Health and Human Services, Office of Disease Prevention and Health Promotion 2010a). Website creators should heed such guidelines to ensure the development of more helpful websites.

Another cost-efficient way of delivering genetics information is to combine it with other health literacy initiatives currently operating in the United States. For example, the Department of Health and Human Services' (see U.S. Department of Health and Human Services, Office of Disease Prevention and Health Promotion 2010b) National Action Plan to Improve Health Literacy, their Healthy People 2020 initiative, and the health literacy component of the Department of Education's Literacy Information and Communication System (LINCS) are programs aimed at improving the public's health literacy. The LINCS program does not include content related to genetics or genetic testing, but it may provide people with some basic skills that will enable them to more easily navigate the genetic testing terrain. For example, the LINCS website contains an intermediate-level education module titled "Making Good Health Decisions," which includes a section related to media messages about prescription drugs. A similar section on DTC genetic test advertisements could readily be added to this module. Compared with the LINCS program, whose focus is primarily on general literacy, the Department of Health and Human Services initiatives are even more relevant to our purpose because they attend primarily to the health part of health literacy. The Action Plan is aimed at modifying information delivery so that it is accessible to those whose general literacy as well as health literacy is fairly low. Although the Action Plan does not specifically mention genetics education, its broad-based recommendations for collaboration among various government agencies, health care providers, public health officers, professional organizations, academic researchers, and philanthropists can help improve the quality and accessibility of health-related information and can be used to guide genetics information delivery.
In addition to making existing genetics information resources accessible, the public should also be trained to extract high-quality, usable data from the large volume of information on the topic. A localized, privately funded example of this is the Grillo Health Information Center in Boulder, Colo., which provides the public with research services and access to credible sources of health information. Expanding such services could be facilitated by an infusion of government and private funding or resources. One suggestion is to make more extensive use of health science librarians (Tarver 2010). If health science librarians were deployed to train librarians at public libraries to navigate more fluidly through health science literature and credible genetics information resources, these public librarians could in turn convey their knowledge to library patrons. This could promote wider use of existing reliable resources and, perhaps, prevent information overload. In addition, Tarver (2010) recommends creating partnerships between health science librarians and other professionals, including public health professionals and health care providers in an effort to improve not only professionals' literacy but also their ability to communicate knowledge to consumers. This increased use of health science librarians would require a collaboration with the National Institutes of Health, as National Library of Medicine personnel would be integral to implementing such a plan.

\section{Limitations and Further Research}

We recognize a few limitations in our current research. One limitation is its use of a college student sample. The recent experiment at the University of California, Berkeley, suggests that examining the characteristics of a college student sample is highly relevant, given that they may be increasingly targeted as potential consumers of these products. That said, to obtain a more complete picture of whether there is a general tendency toward underconfidence among the general population, it will be necessary to study a sample with a more diverse educational background. Given that students who had taken a biology course tended to be more underconfident than their counterparts who had not taken a biology course, it is possible that a lower level of education could alter the direction of miscalibration. In particular, further research should examine at-risk populations such as those with a family history of diseases known or believed to have a significant genetic component. With an unfavorable family background, these people may be especially motivated to learn more about genetic science and genetic tests. While this can potentially lead to more learning, the high level of personal relevancy may make these people especially vulnerable to DTC marketing tactics. Although improving genetic literacy can help these people better understand the relationship between family history and diseases with a significant genetic component, as Bone, France, and Aikin (2009) explain, the ability to process information is negatively affected by heightened emotion. At a minimum, at-risk consumers should be aware of this influence on their information processing and, consequently, on their decisions. Although we controlled for the influence of family history in Study 2, more focused research is needed to examine the behavior and responses of these people in terms of knowledge seeking and decision making. 
Although Study 2 provides some evidence that an educational intervention can improve both genetic literacy and knowledge calibration in this area, we addressed only one form of education and selected feedback mechanisms to a limited audience. Further research is needed to determine whether this educational intervention will have the same results when administered to a larger and more diverse population and how other educational interventions may be more or less effective in enhancing genetic literacy and knowledge calibration among the general public. Moreover, as Silk et al. (2008) recommend for nutrition literacy education, further research into genetic literacy education should include an evaluation of the long-term as well as short-term outcomes and social benefits of myriad educational interventions.

Also deserving of further inquiry are the causes of knowledge miscalibration and the processes through which knowledge calibration can affect consumers' decision making about DTC genetic tests. Alba and Hutchinson (2000) issued a call for more research on knowledge calibration in general. Although our research contributes to this understanding by identifying the existence and direction of miscalibration in genetic knowledge and by showing the extent to which at least one type of educational intervention helps narrow the calibration gap, we did not explicitly test how such miscalibration may influence consumer decision making. Further research can explore the effect of miscalibration at various stages of consumers' decision-making process, such as their information seeking, information processing, susceptibility to emotional appeals and other marketing tactics, and their final purchase decisions. Furthermore, even if educational interventions succeed in improving genetic literacy and calibration, personality traits and environmental factors can play a role in consumer decision making (Huston 2010; Rotfeld 2008). In view of our conclusion in Study 1 regarding the main drivers of purchase intention as well as observations from financial literacy research, even the best educational intervention will still leave ample room for suboptimal decision making. Future studies should examine these potential interfering factors alongside knowledge calibration.

\section{Appendix: Genetic Knowledge Calibration Survey Questions}

\section{Sample GLAI Question (for the complete questionnaire, see Bowling, Acra, et al. 2008)}

What is the relationship among genes, DNA, and chromosomes?

a. Genes are composed of DNA and lie within chromosomes.

b. Genes are separate entities from either DNA or chromosomes.

c. Genes are found only in chromosomes and not DNA.

d. Genes are found only in DNA and not chromosomes.

e. Chromosomes are composed of genes but not DNA.

\section{Genetics Domain Self-Efficacy}

1. How familiar are you with genetic concepts? ("not familiar at all/extremely familiar")
2. How clear an idea do you have about which characteristics of genetic tests are important in providing you best results? ("not very clear/very clear")

3. I know a lot about genetics. ("disagree/agree")

4. How would you rate your knowledge about genetics relative to the rest of the population? ("least knowledgeable people/ most knowledgeable people")

\section{GLAI Task-Specific Self-Efficacy}

1. (Task self-efficacy level) Of the 25 genetic literacy questions that we asked earlier, how many questions do you think you have answered correctly?

2. (Task self-efficacy strength) For the number you gave above, how confident are you that you answered that many questions correctly? (0\%-100\%)

\section{Attitude and Purchase Intention}

1. How do you feel about manufacturers selling genetic tests directly to consumers? ("very negatively/very positively")

2. How likely are you to purchase a genetic test directly from the manufacturer of such tests? ("very unlikely/very likely")

\section{References}

Alba, Joseph W. and J. Wesley Hutchinson (2000), "Knowledge Calibration: What Consumers Know and What They Think They Know," Journal of Consumer Research, 27 (2), 123-56.

American Society of Human Genetics (2004), "Statement on the Importance of Participation of Scientists in K-12 Science Education," (accessed May 29, 2010), [available at http://www. ashg.org/education/k12statement.shtml].

Ashford, Susan J., Ruth Blatt, and Don VandeWalle (2003), "Reflections on the Looking Glass: A Review of Research on Feedback-Seeking Behavior in Organizations," Journal of Management, 29 (6), 773-99.

Bandura, Albert (1997), Self-Efficacy: The Exercise of Control. New York: Freeman.

Berg, Cheryl and Kelly Fryer-Edwards (2008), "The Ethical Challenges of Direct-to-Consumer Genetic Testing," Journal of Business Ethics, 77 (1), 17-31.

Bloss, Cinnamon S., Nicholas J. Schork, and Eric J. Topol (2011), "Effect of Direct-to-Consumer Genomewide Profiling to Assess Disease Risk," New England Journal of Medicine, 364 (6), 524-34.

Bone, Paula Fitzgerald, Karen Russo France, and Kathryn J. Aikin (2009), "On Break-up Clichés Guiding Health Literacy's Future," Journal of Consumer Affairs, 43 (2), 185-98.

Bowling, Bethany Vice, Erin E. Acra, Lihshing Wang, Melanie F. Myers, Gary E. Dean, Glenn C. Markle, et al. (2008), "Development and Evaluation of a Genetics Literacy Assessment Instrument for Undergraduates," Genetics, 178 (January), $15-22$.

, Carl A. Huether, Lihshing Wang, Melanie F. Myers, Glenn C. Markle, Gary E. Dean, et al. (2008b), "Genetic Literacy of Undergraduate Non-Science Majors and the Impact of Introductory Biology and Genetics Courses," Bioscience, 58 (7), 654-60. 
Burton, Scot, Abhijit Biswas, and Richard Netemeyer (1994), "Effects of Alternative Nutrition Label Formats and Nutrition Reference Information on Consumer Perceptions, Comprehension, and Product Evaluations," Journal of Public Policy \& Marketing, 13 (Spring), 36-47.

Caswell, Julie A., Yumei Ning, Fang Liu, and Eliza M. Mojduszka (2003), "The Impact of New Labeling Regulations on the Use of Voluntary Nutrient-Content and Health Claims by Food Manufacturers," Journal of Public Policy \& Marketing, 22 (Fall), $147-58$.

Christensen, K.D., T.E. Jayaratne, J.S. Roberts, S.L.R. Kardia, and E.M. Petty (2010), "Understandings of Basic Genetics in the United States: Results from a National Survey of Black and White Men and Women," Public Health Genomics, 13 (7/8), 468-76.

Colliver, Victoria (2010), "Ethics of UC Berkeley's Gene Testing Questioned," San Francisco Chronicle, (May 21), (accessed May 26, 2010), [available at http://articles.sfgate.com/2010-0521/bay-area/20907654_1_genetic-testing-test-results-testingkits].

Condit, Celeste Michelle (2010), "Public Understandings of Genetics and Health," Clinical Genetics, 77 (1), 1-9.

Contento, Isobel R., Jill Randell, and Charles E. Basch (2002), "Review and Analysis of Evaluation Measures Used in Nutrition Education Intervention Research," Journal of Nutrition Education and Behavior, 34 (1), 2-25.

Davis, Terry C., Julie Gazmararian, and Estela M. Kennen (2006), "Approaches to Improving Health Literacy," Journal of Health Communication, 11 (6), 551-54.

Etchegary, H., M. Capelli, B. Potter, M. Vloet, I. Graham, M. Walker, and B. Wilson (2010), "Attitudes and Knowledge About Genetics and Genetic Testing," Public Health Genomics, 13 (2), 80-88.

Fox, Jonathan, Suzanne Bartholomae, and Jinkook Lee (2005), "Building the Case for Financial Education," Journal of Consumer Affairs, 39 (1), 195-214.

Gooding, Holly C., Kurt Organista, Jeffrey Burack, and Barbara Bowles Biesecker (2006), "Genetic Susceptibility Testing from a Stress and Coping Perspective," Social Science and Medicine, $62(8), 1880-90$.

Gross, Rachel (2010), “A Few Wrinkles in U.C. Berkeley's Plan to Test Freshmen's Genes," The Bay Area, (May 24), (accessed May 26, 2010), [available at http://bayarea.blogs.nytimes.com/2010/ 05/24/a-few-wrinkles-in-u-c-berkeleys-plan-to-test-freshmensgenes/].

Hattie, John and Helen Timperley (2007), "The Power of Feedback," Review of Educational Research, 77 (1), 81-112.

Hofman, Karen, Ellen S. Tambor, Gary A. Chase, Gail Geller, Ruth R. Faden, and Neil A. Holtzman (1993), "Physicians' Knowledge of Genetics and Genetic Tests," Academic Medicine, 68 (8), 625-32.

Hogarth, Jeanne M. (2006), "Financial Education and Economic Development," paper presented at G8 International Conference on Improving Financial Literacy Moscow, Russian Federation (November 29-30).

Huston, Sandra J. (2010), "Measuring Financial Literacy," Journal of Consumer Affairs, 44 (2), 296-316.

Jacoby, Jacob, Donald E. Speller, and Carol A. Kohn (1974), "Brand Choice Behavior as a Function of Information Load," Journal of Marketing Research, 11 (February), 63-69.
Javitt, Gail H. (2007), "In Search of a Coherent Framework: Options for FDA Oversight of Genetic Tests," Food and Drug Law Journal, 62 (4), 617-52.

Johnson, J. David, Donald O. Case, and James E. Andrews (2005), "Genomics: The Perfect Information-Seeking Research Problem," Journal of Health Communication, 10 (4), 323-29.

Kluger, Avraham N. and Angelo DeNisi (1996), "The Effects of Feedback Interventions on Performance: A Historical Review, a Meta-Analysis, and a Preliminary Feedback Intervention Theory," Psychological Bulletin, 119 (2), 254-84.

Kozup, John and Jeanne M. Hogarth (2008), "Financial Literacy, Public Policy, and Consumers' Self-Protection: More Questions, Fewer Answers," Journal of Consumer Affairs, 42 (2), 127-36.

Lanie, Angela D., Toby Epstein Jayaratne, Jane P. Sheldon, Sharon L.R. Kardia, Elizabeth Anderson, Merle Feldbaum, and Elizabeth M. Petty (2004), "Exploring the Public Understanding of Basic Genetic Concepts," Journal of Genetic Counseling, 13 (4), 305-320.

Liu, Yuping and Yvette Pearson (2008), "Direct-to-Consumer Marketing of Predictive Medical Genetic Tests: Assessment of Current Practices and Policy Recommendations," Journal of Public Policy \& Marketing, 27 (Fall), 131-48.

McGuire, Amy L., Christina M. Diaz, Tao Wang, and Susan G. Hilsenbeck (2009), "Social Networkers' Attitudes Toward Direct-to-Consumer Personal Genome Testing," American Journal of Bioethics, 9 (6/7), 3-10.

McInerny, Joseph (2002), "Education in a Genomic World," Journal of Medicine and Philosophy, 27 (3), 369-90.

Mitchell, Andrew A. and Peter A. Dacin (1996), "The Assessment of Alternative Measures of Consumer Expertise," Journal of Consumer Research, 23 (3), 219-39.

Moorman, Christine (1996), “A Quasi Experiment to Assess the Consumer and Informational Determinants of Nutrition Information Processing Activities: The Case of the Nutrition Labeling and Education Act," Journal of Public Policy \& Marketing, 15 (Spring), 28-44.

Morren, Mattijn, Mieke Rijken, Arianne N. Baanders, and Jozien Bensing (2007), "Perceived Genetic Knowledge, Attitudes Towards Genetic Testing, and the Relationship Between These Among Patients with a Chronic Disease," Patient Education and Counseling, 65 (2), 197-204.

Oskamp, Stuart (1962), "The Relationship of Clinical Experience and Training Methods to Several Criteria of Clinical Prediction," Psychological Monographs, 76 (28), 20-31.

Park, Cheong-Yi (2001), "News Media Exposure and Self-Perceived Knowledge: The Illusion of Knowing," International Journal of Public Opinions Research, 13 (4), 419-25.

Pearson v. Shalala (1999) 164 F.3d 650 (D.C. Cir.), reversing, 14 F. Suppp. 2d 10 (D.D.C. 1998).

Perry, Vanessa Gail (2008), "Is Ignorance Bliss? Consumer Accuracy in Judgements About Credit Ratings," Journal of Consumer Affairs, 42 (2), 189-205.

Rose, Abigail, Nikki Peters, Judy A. Shea, and Katrina Armstrong (2005), "The Association Between Knowledge and Attitudes About Genetic Testing for Cancer Risk in the United States," Journal of Health Communication, 10 (4), 309-321.

Rotfeld, Herbert Jack (2008), "Financial Aliteracy," Journal of Consumer Affairs, 42 (2), 306-309. 
Sanderson, Saskia C. and Jane Wardle (2008), "Associations Between Anticipated Reactions to Genetic Test Results and Interest in Genetic Testing: Will Self-Selection Reduce the Potential for Harm," Genetic Testing, 12 (1), 59-66.

Schraw, Gregory and Teresa DeBacker Roedel (1994), "Test Difficult and Judgment Bias," Memory and Cognition, 22 (1), 63-69.

Shute, Valerie J. (2008), "Focus on Formative Feedback," Review of Educational Research, 78 (1), 153-89.

Silk, Kami J., John Sherry, Brian Winn, Nicole Keesecker, Mildred A. Horodynski, and Aylin Sayir (2008), "Increasing Nutrition Literacy: Testing the Effectiveness of Print, Web Site, and Game Modalities," Journal of Nutrition Education and Behavior, 40 (1), 3-10.

Spader, Jonathan, Janneke Ratcliffe, Jorge Montoya, and Peter Skillern (2009), "The Bold and the Bankable: How the Nuestro Barrio Telenovela Reaches Latino Immigrants with Financial Education," Journal of Consumer Affairs, 43 (1), 56-79.

Stein, Rob (2010), "Company Plans to Sell Genetic Testing Kit at Drugstores," The Washington Post, (May 11), (accessed May 26, 2010), [available at http://www.washingtonpost.com/wp-dyn/ content/article/2010/05/10/AR2010051004904.html].

Tarver, Talicia (2010), "Genomics: A New Challenge in Consumer Health Information Literacy," Journal of Hospital Librarianship, 10 (1), 23-32.

Terry, Mark (2008), "Direct-to-Consumer Testing and Its Impact on the Lab Market," Washington G2 Reports, (January 24), (accessed January 30, 2010), [available at http://www.g2reports. com/issues/advisory/advisory/mark_terry/235-1.html].
University of California, Berkley (2010), "Bring Your Genes to Cal," On the Same Page, (accessed May 28, 2010), [available at http://onthesamepage.berkeley.edu/archive/2010-genes/faq. php\#book].

U.S. Department of Health and Human Services, Office of Disease Prevention and Health Promotion (2010a), "Health Literacy Online: A Guide to Writing and Designing Easy-to-Use Health Web Sites," (accessed December 24, 2010), [available at http:// www.health.gov/healthliteracyonline/].

(2010b), "National Action Plan to Improve Health Literacy," (accessed December 24, 2010), [available at http://www. health.gov/communication/hlactionplan/].

Vladeck, David C. (2000), "Truth and Consequences: The Perils and Half-Truths and Unsubstantiated Claims for Dietary Supplements," Journal of Public Policy \& Marketing, 19 (Spring), $132-38$.

Walstad, William B., Ken Rebeck, and Richard MacDonald (2010), "The Effects of Financial Education on the Financial Knowledge of High School Students," Journal of Consumer Affairs, 44 (2), 336-57.

Wiener, Josh and Tabitha Doescher (2008), "A Framework for Promoting Retirement Savings," Journal of Consumer Affairs, 42 (2), 137-64.

Williams-Jones, Bryn (2003), "Where There's a Web, There's a Way: Commercial Genetic Testing and the Internet," Community Genetics, 6 (1), 46-57.

- and Vural Ozdemir (2008), "Challenges for Corporate Ethics in Marketing Genetic Tests," Journal of Business Ethics, 77 (1), 33-44. 